\title{
PERFIL E HÁBITOS DOS CONSUMIDORES DE CHOCOLATE NA CIDADE DE ERECHIM/RS
}

\section{Profile and habits of chocolate consumers in the city of Erechim/RS}

\author{
Daniele Bonatto Senhori ${ }^{1 ;}$ Rodrigo André Cechett ${ }^{2}$
}

\begin{abstract}
${ }^{1}$ Pós Graduanda em Marketing, Comunicação e Branding na URI Erechim. Graduada em Marketing. Técnica em Vendas. E-mail: dani.senhori02@gmail.com

${ }^{2}$ Graduado em Administração de Empresas. Mestre em Administração. Especialista em Marketing. Empreendedor. Assessor de Marketing e Professor na URI Erechim.E-mail: cechett@uricer.edu.br
\end{abstract}

Data do recebimento: 28/05/2021 - Data do aceite: 17/06/2021

RESUMO: O valor da marca tem sido um tema de estudo recorrente pelos pesquisadores da área, em que buscam mostrar sua importância e reiterar sua participação perante a escolha do consumidor pela marca. Cada vez mais, as marcas precisam mostrar seus atributos positivos para os consumidores, que as diferenciem das demais, procurando satisfazer os desejos e necessidades de seus consumidores, a fim de que esses se identifiquem, consumam e tornem-se fiéis. Isso acontece também no mercado consumidor de chocolates, onde as marcas precisam aumentar os esforços para criar um relacionamento forte com os consumidores, com o intuito de torná-los leais à marca, visto ser um setor extremamente competitivo, reforçando a importância que as empresas desse ramo precisam ter com sua distribuição, buscando ter o produto em todos os pontos de venda possíveis, fazendo com que o consumidor sempre veja e lembre-se da marca. Este estudo pretende identificar qual o perfil e hábitos de consumo dos consumidores de chocolate na cidade de Erechim/RS. Em termos metodológicos, o referencial teórico permitiu recolher informações necessárias para aprofundamento do tema, possibilitando maior interação e entendimento sobre alguns conceitos de marcas e também do setor de chocolates no Brasil. Para coleta dos dados, elaborou-se um questionário estruturado, com 17 perguntas fechadas, divididas em dois módulos. O questionário foi aplicado na cidade de Erechim/RS, para pessoas que consomem chocolates. Alcançou-se um total de 143 questionários, que serviram para efetuar a análise dos resultados. Além disso, sugere-se a utilização desta metodologia para desenvolver novos estudos sobre valor da marca para outros segmentos e ramos de negócios, ou até mesmo para aprofundar os estudos no mercado de chocolates. Como principais resultados da pesquisa, pode-se afirmar que os con- 
sumidores de chocolate na cidade de Erechim optam pela escolha de marcas que prezam pela qualidade do produto oferecido e veem isso como um diferencial. A grande maioria compra por loja física e encontra facilmente o produto de sua preferência no comércio local da cidade. Também, como resultado importante, a maioria dos entrevistados não se mostraram fiéis às marcas que colocaram como suas prediletas, reiterando a importância de as marcas criarem um vínculo mais forte com seus consumidores, fazendo com que se tornem leais. Grande maioria dos respondentes afirmou que ao consumir chocolate ficam felizes, ou seja, a marca precisa trabalhar para entregar o máximo de qualidade e experiência para este consumidor, pois certamente ele lembrará desse sentimento bom quando for escolher seu chocolate.

Palavras-chave: Marca. Consumidor. Chocolates.

ABSTRACT: The value of the brand has been a subject of recurrent study by researchers in the area, in which they seek to show its importance and reiterate their participation in the consumer's choice for the brand. Increasingly, brands need to show their positive attributes to consumers, which differentiate them from others, seeking to satisfy the desires and needs of their consumers, in order to identify, consume and become loyal. This also happens in the chocolate consumer market, where brands need to increase efforts to create a strong relationship with consumers, in order to make them loyal to the brand, since it is an extremely competitive sector, reinforcing the importance that companies of this need to have with their distribution, making use of the product in all possible points of sale, making the consumer always see and remember the brand. This study aims to identify the profile and consumption habits of chocolate consumers in the city of Erechim/RS. In methodological terms, the theoretical framework permitted to collect necessary information to deepen the theme, allowing a greater interaction and understanding about some concepts of brands and also of the chocolate sector in Brazil. For data collection, a structured questionnaire was elaborated, with 17 closed questions, divided into two modules. The questionnaire was applied in the city of Erechim / RS to people who consume chocolates. A total of 143 questionnaires were reached, which were used to analyze the results. In addition, it is suggested to use this methodology to develop new studies on brand value for other segments and branches of business, or even to deepen studies on the chocolate market. As the main results of the survey, it can be stated that chocolate consumers in the city of Erechim choose brands that value the quality of the product offered and see this as a differential, the vast majority buy in physical stores and easily find the product from your preference in the city's local businesses. Also, as an important result, most respondents were not loyal to the brands they placed as their favorites, reiterating the importance of brands creating a stronger bond with their consumers, making them become loyal. The vast majority of respondents said that when consuming chocolate they are happy, that is, the brand needs to work to deliver the maximum quality and experience to this consumer, as he will certainly remember this good feeling when choosing his chocolate.

Keywords: Brand. Consumer. Chocolates. 


\section{Introdução}

O valor da marca significa para o cliente uma promessa de um produto de qualidade superior (funcional ou emocional). Ao fazer suas compras, muitos clientes optam por adquirir produtos ofertados de uma marca conhecida, pelo fácil acesso, pelo nome, ou pela diferenciação que esta marca possui em relação a outras marcas. Assim, como a marca é mais que apenas o nome que expressa, é importante também dar atenção à percepção que o cliente associa da marca ao produto (SERRALVO et al., 2011).

Com o mundo cada vez mais dinâmico, uma das consequências da globalização foi a crescente oferta de produtos e serviços, fazendo com que os gestores despertassem para novas formas de trabalhar dentro das organizações. Conforme Kotler, Kartajaya e Iwan (2010), a onda tecnológica facilita a disseminação de informações permitindo aos consumidores participar da criação dos valores da marca.

No setor de chocolates, não poderia ser diferente. Com novas tecnologias e formas mais inteligentes de desenvolver processos e produtos, aliados ao consumidor cada vez mais exigente, torna-se extremamente importante pensar em novos formatos de trabalho, com o intuito de atendê-los e fidelizá-los, visto ser um mercado altamente competitivo.

Segundo Mancini (2019), o consumo de chocolate faz parte da vida do brasileiro: $75 \%$ da população o consome e destes $56 \%$ são mulheres e $35 \%$ não o trocariam por outro alimento, retratando dados da Abicab. Contudo, no mercado de chocolates há bastante concorrência, com indústrias de grande e pequeno porte que fabricam produtos diferenciados para seus consumidores mais exigentes. $\mathrm{O}$ consumo de chocolates foi ganhando força ao longo dos anos, que hoje tem um setor do supermercado, por exemplo, destinado exclusivamente para esses produtos, com as mais diversas marcas disputando um espaço na gôndola.

Dessa forma, considerando o exposto acima, o presente estudo visa a identificar qual é o perfil do consumidor e quais são seus hábitos de consumo na cidade de Erechim/ RS, identificando também qual a marca mais lembrada entre eles, ao questioná-los sobre os atributos da marca.

\section{Contextualização e relevância da marca}

Esta seção é composta por uma revisão dos conceitos sobre valor da marca e de trabalhos relativos à mensuração do valor da marca.

De acordo com Keller e Machado (2006, p.7), “o significado incorporado em uma marca pode ser bastante profundo, e o relacionamento entre ela e o consumidor pode ser visto como um tipo de vínculo ou pacto.” Os consumidores entregam à marca sua fidelidade e confiabilidade, esperando que ela traga benefícios e corresponda suas expectativas de forma positiva. Ainda segundo Keller e Machado (2006) quando os consumidores consomem e/ou adquirem produtos de determinada marca, estão comunicando para outras pessoas - ou a si mesmo - o tipo de pessoa que são ou que gostariam de ser.

Esse encantamento proposto pela magia das marcas estabelece a lógica de consumo, real ou imaginária, pois passa a ter existência concreta e a justificar comportamentos. Com isso, o consumidor busca prazer e o bem-estar adquirindo a marca (SERRALVO, et al., 2011).

A marca, pode ser conceituada como a união de atributos tangíveis e intangíveis, que caracterizada por um logotipo, por exemplo. Esses atributos criam influência e geram 
valor, se gerenciados de forma adequada, entregando soluções aos seus consumidores (MARTINS, 2006).

Segundo o INPI - Instituto Nacional da Propriedade Industrial (2017), a marca é considerada um sinal que identifica os produtos ou serviços de uma empresa no mercado, e que a diferencia das demais marcas. Quando consumidores potenciais são capazes de distinguir um produto pela marca, eles podem ficar pré-dispostos a desembolsar um valor maior para adquirir esse produto de determinada marca (CHURCHILL JR.; PETER, 2010). Neste sentido, os atributos de uma marca se tornam fundamentais para que seus consumidores assimilem e identifiquem a marca.

Para Keller e Machado (2006) a escolha correta dos elementos da marca deve ser pensada por meio de uma estratégia, a qual a união dos elementos possa ter grande contribuição para a criação do brandy equity, que nada mais é do que o valor adicional que se coloca em um produto ou serviço (valor da marca), influenciando na forma com que o consumidor pensa e age em relação à marca. Alguns dos elementos considerados importantes pelos autores são expostos a seguir:

- Nome: Uma marca necessita ter um nome que seja facilmente lembrado e sugira a classe do produto, servindo também para transmitir seu posicionamento, que seja divertido ou interessante, rico em potencial, criativo e transferível para uma ampla variedade de produtos, além da possibilidade de ser protegido jurídica e corporativamente. $\mathrm{O}$ nome da marca deve ser escolhido de forma criteriosa, pois deve ser capaz de capturar o tema central ou as associações-chave de um produto de maneira direta. Ou seja, os nomes de uma marca devem realizar a comunicação de forma breve e efetiva.
- Domínios na internet: Considerado importante pelos autores é a existência de domínios na internet. Com o advento da internet muitas empresas reivindicam cada vez mais espaço nela. Com isso, com o uso dos domínios, a marca é capaz de proteger seu nome da utilização indevida em outros domínios não autorizados.

- Logotipos e símbolos: Elementos visuais, os logotipos e símbolos, tem papel importante na construção do brandy equity, principalmente quando se refere a uma lembrança da marca pelo consumidor. É muito antiga a utilização dos logotipos como um meio de apontar a origem, propriedade ou associação, como por exemplo, as famílias e os países que utilizam logotipos a séculos para representar seu nome visualmente. Um dos benefícios de se utilizar os elementos visuais, é a facilidade pelo qual são reconhecidos, além de identificarem os produtos, ligando-os à memória do consumidor.

- Personagem: Este é um tipo especial de símbolo da marca. Geralmente é utilizado em propagandas e pode desempenhar papel importante nas campanhas publicitárias, podendo ser representado com forma de animação ou através de figuras reais. O personagem da marca tem a importante missão de transmitir a personalidade da marca e despertar a simpatia. Também ajudam a marca a romper a saturação do mercado, além de ajudá-la a transmitir um importante benefício do produto. Porém, muitas vezes os personagens das marcas precisam ser atualizados, com o passar do tempo, para que se mantenha relevância destes para o mercado alvo.

- Slogan: Os slogans são capazes de comunicar informações descritivas e persuasivas sobre a marca por meio de frases curtas. Costumeiramente eles aparecem 
nas propagandas, embalagens e em outros aspectos do programa de marketing.

- Jingles: São mensagens musicais curtas nas quais o tema central é a marca. Criado por profissionais da música, geralmente os jingles são capazes de ficar registrados quase que, permanentemente, na mente dos ouvintes. Podem ser considerados um slogan musical ampliado da marca, assim, podendo ser classificado como um elemento da marca. Porém, devido à sua musicalidade, não tem capacidade de transmitir outros elementos da marca.

- Embalagem: A criação de uma embalagem envolve diversas atividades de projeto, produção de recipientes e rótulos para um produto. Do ponto de vista, tanto da empresa quanto dos consumidores, as embalagens devem cumprir alguns quesitos, tais como: identificar a marca, transmitir informações descritivas e persuasivas, facilitar o transporte e a proteção do produto, auxiliar na armazenagem doméstica e auxiliar no consumo do produto. Para que os objetivos de marketing sejam cumpridos e satisfaçam os desejos dos consumidores, a embalagem deve ser funcional e esteticamente bonita, tendo seus componentes definidos cuidadosamente. Ela deve ser bem escolhida, pois os consumidores relacionam a marca com a aparência de sua embalagem.

Segundo Serralvo et al. (2011) a construção da identidade da marca pode ser tida como fator fundamental para qualquer estratégia. Uma marca considerada forte no mercado deve ter uma identidade de marca clara, para que possa formar na mente dos consumidores a percepção de uma marca sólida. Hoje, os consumidores também estão propensos a buscar fabricantes que se preocupem com questões sociais e ambientais. Dessa forma, ressalta-se também a importância de se ter uma identidade de marca corporativa bem alinhada com os objetivos da empresa, para que possa passar ao consumidor mais credibilidade.

A empresa, representada pela marca, deve ser vista como fabricante de um desejo dos consumidores e ter credibilidade em suas ofertas. A marca tende a ter uma característica essencial ao consumidor, precisa criar e manter energia suficiente para não se tornar apenas mais uma figurante no setor. Marcas desinteressantes e sem personalidade, normalmente não são associadas a inovações, assim, perdendo credibilidade e a lealdade do consumidor. Em termos mais formais, a relevância da marca ocorre quando duas condições são atendidas: quando o cliente possui um desejo e encontra sua realização em uma marca; e quando o cliente compra uma marca (AAKER, 2011).

Ainda segundo Aaker (2011), a relevância da marca não está apenas em derrotar a concorrência, mas torná-la irrelevante ao convencer seus clientes a consumirem apenas a marca, diante de qualquer outra alternativa. Isso pode ter como consequência um mercado onde não existirá concorrência por um longo período de tempo ou a concorrência será muito fraca comparada à sua marca.

Para Serralvo et al. (2011) a influência da marca sobre os consumidores resulta da diferenciação do produto, da compensação dos preços altos, da geração de novos desejos e necessidades, entre outros. Sendo assim, os autores concluem que as marcas representam uma promessa da garantia da satisfação para o cliente, seu bem-estar e ainda, da expectativa que o bom desempenho do produto irá efetivamente ocorrer após sua compra.

Neste sentido, Kotler e Keller (2006) explicam que é importante entregar uma proposta de valor consistente ao consumidor, que mostre todo o conjunto de benefícios que a empresa pretender entregar ao cliente. 
O sistema de entrega de valor deve ser bem trabalhado, pois inclui todas as experiências que os consumidores terão ao longo de tempo em que estiver no processo de compra, ou seja, entre obter e usar a oferta.

Para Churchill Jr. e Petter (2012) a utilização da marca é uma forma de distinguir os produtos na mente dos potenciais consumidores, sendo que estes podem dispor de um esforço extra e gastar mais dinheiro para adquirir determinada marca.

Quanto mais o consumidor adquire uma marca, mais ele a ajuda a construir sua identidade, porém, a construção da marca mudou substancialmente nos últimos anos. Antigamente, as marcas levavam anos ou décadas para se consolidarem, com base nos atributos dos produtos, por intermédio, principalmente, da propaganda, e enfrentavam pouca ou nenhuma concorrência. Nos dias atuais, as marcas são construídas muito mais rapidamente, de forma a fazer com que o tempo de desenvolvimento de inovações fosse reduzido, fazendo com que essas inovações possam basear-se em ideias e não apenas em produtos. Utilizam a propaganda apenas como mais um dos muitos fatores criadores de marcas, pois no mercado altamente competitivo existente, aumenta a dificuldade de destacar-se no mercado (SERRALVO, et al., 2011).

A denominação de "marca" passou a ser tratada com maior relevância e cuidado em função da ascensão da produção em massa, no século XIX. Na era da máquina, a competitividade da marca tornou-se uma necessidade, pois com a produção de itens semelhantes, a diferença precisava ser criada baseada em sua imagem (SERRALVO, et al., 2011).

Segundo Oliveira et al. (2012), após a Idade Média as marcas vieram sendo utilizadas para identificar e proteger o consumidor, tendo em vista que as marcas indicam qualidade, origem e, também, os benefícios em adquirir produtos ou serviços. As mar- cas foram empregadas durante a Revolução Industrial, desencadeando o processo de comunicação e as ações de marketing, onde sua evolução chegou até a forma dos dias atuais. Nos Estados Unidos, a indústria farmacêutica e alimentícia foram as primeiras no uso destas marcas. Como principais ferramentas de desenvolvimento e fixação das marcas, destacaram a propaganda e a promoção de vendas, com o intuito de bem posicionar a marca para o mercado.

\section{Valor da marca segundo Aaker}

Segundo Aaker (1998), os ativos do brand equity somam ou subtraem valor para os consumidores e auxiliam a compreender, processar e armazenar uma enorme quantidade de informações a respeito de produtos e marcas. Outro fator capaz de afetar a confiança do consumidor, no momento da tomada de decisão de compra, é o impacto que o nome da marca tem no valor do mercado

Para Oliveira et al. (2012) um dos elementos considerados mais críticos para formação do valor da marca é estar "na mente dos consumidores". Partindo dessa premissa, os princípios culturais e sociais são de muita valia para se obter apelos intuitivos que possam fazer com que o consumidor associe a marca em determinado momento. Quando mais espontânea e natural for a associação com a marca, mais diferencial ela terá, e maior será a possibilidade de o consumidor vir a adquiri-la.

O valor da marca é expresso pelo seu valor de venda. Esse é o resultado de quanto os consumidores lembram da marca, somado à fidelidade de seus clientes e à facilidade com que os mesmos associam a marca (DIAS et al., 2010).

Para Kotler e Keller (2006) o brand equity é o valor agregado relacionado aos produtos e serviços. Esse valor pode ser notado na for- 
ma como os consumidores pensam, sentem e agem em relação à marca, como também nos preços, na participação de mercado e no lucro que a marca é capaz de gerar à empresa. O brand equity é um ativo intangível capaz de representar o valor psicológico e financeiro para a empresa. Já para Dias et al. (2010) brand equity é o resultado de quanto o consumidor lembra ou tem consciência da marca, somado à fidelidade de seus clientes e à força associada à marca.

Para Aaker (1998), marcas fortes podem ser ativos valiosos para a organização, pois quando existe uma boa estratégia de marketing os profissionais são capazes de desenvolver e manter uma imagem positiva entre os compradores. Como consequência disso, uma reputação de qualidade e valor pode atrair novos clientes, assim como, fidelizar os já existentes à marca ou até mesmo fazê-los experimentarem outros produtos da mesma marca. Assim, as organizações podem elevar suas vendas com custos menores.
A marca é de valor simbólico, composta por benefícios e inconvenientes, servindo para identificar e diferenciar os produtos do mercado. $\mathrm{O}$ valor da marca é considerado um conjunto de ativos e passivos relacionados a uma determinada marca. $\mathrm{O}$ autor, identifica cinco pontos para determinar o valor da marca, como mostrado na Figura 1: lealdade do cliente, consciência do nome da marca, qualidade percebida, associações da marca e outros ativos da marca (AAKER, 1998).

Lealdade à marca: para Aaker (1998), este item representa a escolha de uma determinada marca pelo consumidor, e a probabilidade de ele trocar de marca comparado ao produto ou serviço da concorrência. Quanto maior a lealdade do consumidor com a marca, menor será a probabilidade de trocar de marca, e ir para o concorrente. O autor ressalta que um consumidor satisfeito e leal à marca, irá recomendá-la para outras pessoas, aumentando desta forma a lucratividade da

Figura 1 - Elementos do Valor da Marca

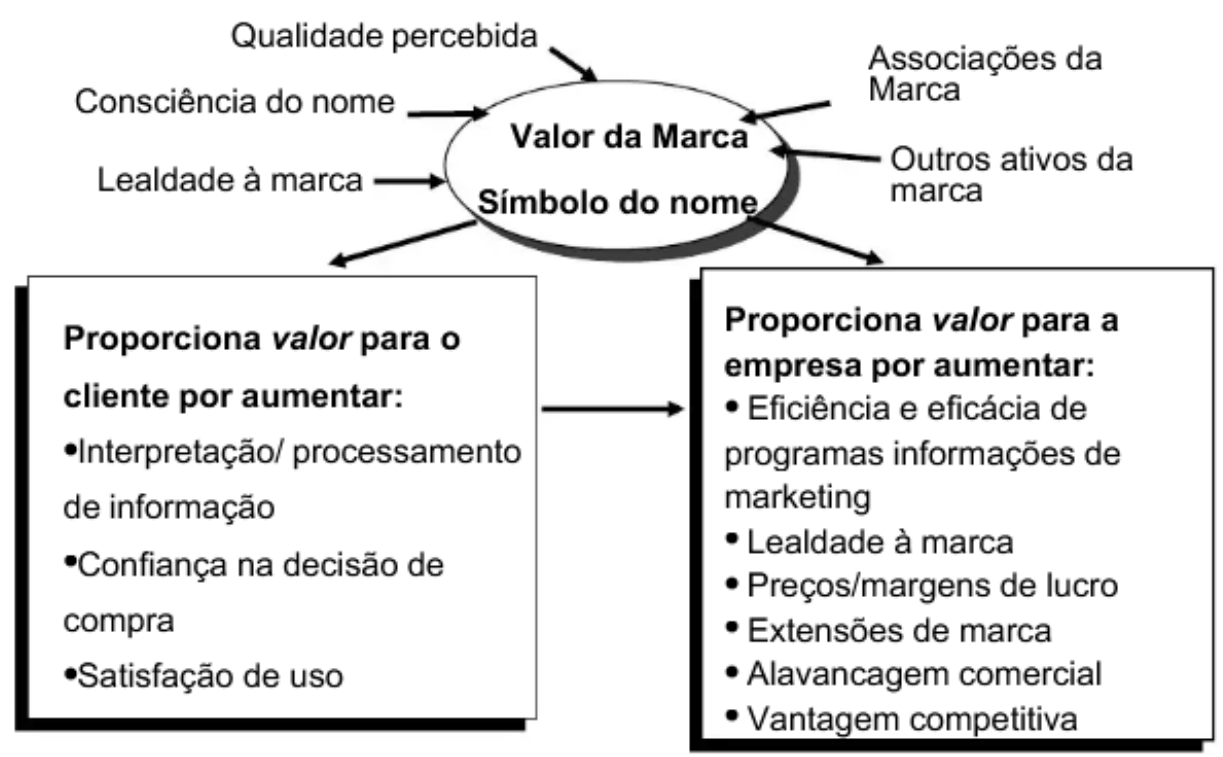

Fonte: CHURCHILL JR.; PETER (2012). 
empresa, além de atrair outros clientes para a empresa, que podem vir a se tornar leais.

Consciência do nome: segundo o autor, a consciência do nome significa a capacidade de o consumidor lembrar-se da marca, no momento da compra de determinado produto ou serviço. Aaker (1998) afirma que é fundamental que a comunicação trabalhada na empresa seja voltada ao reconhecimento da marca. No momento da compra de um produto, se o consumidor conseguir associar a necessidade pelo produto com a marca, a chance de adquirir o produto é maior, pois irá assimilar melhor as características do produto, determinada linha/categoria de produtos.

Qualidade percebida: a qualidade percebida é a percepção que os consumidores têm da qualidade dos produtos e serviços que a empresa trabalha. Os consumidores buscam o menor preço com a maior qualidade dos produtos ou serviços, dessa forma, a qualidade é fator importante e determinante para a empresa, em relação aos seus produtos e serviços, pois está estreitamente ligado ao que o consumidor avalia como importante para si próprio, e que valoriza (AAKER, 1998).

Associações da marca: marcas que possuem grande força no mercado, com avaliações positivas, causadora de experiências boas para seus consumidores, capazes de manter um bom relacionamento com os consumidores, é lembrada mais facilmente. Essa marca está mais presente na cabeça dos consumidores e tem maiores chances de serem adquiridas no ato da compra (AAKER, 1998).

Outros ativos da empresa: todos e quaisquer outros recursos da empresa capazes de agregar valor à marca, tais como patentes, redes de distribuição exclusiva, ou qualquer outro fator que seja capaz de dificultar a atuação de outras marcas no mercado (AAKER, 1998).

\section{O valor da marca para o consumidor}

De acordo com Solomon (2009) o comportamento do consumidor não se trata apenas no ato em si da compra, onde o consumidor paga para adquirir um bem ou serviço. O comportamento do consumidor é muito mais do que isso. A marca tem que estar na cabeça dos consumidores antes mesmo deles cogitarem a hipótese de adquirir o produto ou serviço da empresa, e claro, depois do ato da compra. Estudar o comportamento do consumidor é um bom negócio para a empresa, já que elas existem a fim de satisfazer as necessidades e desejos dos consumidores e, para isso, é importante compreender as pessoas que irão fazer uso do produto ou serviço que a empresa pretende vender.

Neste mesmo sentido, Froemming et al. (2009) afirmam que o comportamento do consumidor foca seus esforços para entender como os consumidores pensam e como se comportam no ato de suprir suas necessidades e seus desejos, através da atividade de consumo.

É fundamental que o comportamento do consumidor seja dinâmico para o desenvolvimento da estratégia de marketing. O ciclo de vida dos produtos está muito curto, dessa forma, muitas empresas se veem obrigadas a procurar formas de inovar em seu meio, a fim de oferecer maior qualidade e informação aos clientes, para continuar obtendo lucros. Sendo assim, é importante que as empresas procurem lançar novos produtos ou serviços, adaptar versões e renovar suas estratégias para continuar no mercado.

Ainda, segundo Peter e Olson (2009), o comportamento do consumidor pode ser diretamente observado e avaliado por meio das ações físicas dos consumidores. Através disso, é possível que as empresas criem es- 
tratégias com o objetivo que vendas sejam efetuadas e consequentemente os lucros nos negócios aumentem.

Para Schiffman e Kanuk (2015) o comportamento do consumidor tem foco em todas as ações dos clientes que envolvam a forma de como eles usarão os recursos disponíveis ao adquirir um produto ou serviço: onde compram, o que compram, com qual frequência, etc. A empresa precisa conhecer e entender seu consumidor, qual seus desejos, o que pensam, como trabalham. Precisa conhecer quais são suas atitudes e as do grupo a que pertencem, os meios que o influenciam, para que possa pensar em estratégias que atinjam seu público alvo, como também, saber onde alcançá-los.

\section{Setor de chocolates no brasil}

Segundo Ministério da Agricultura, Pecuária e Abastecimento (2020), o Brasil, que já foi o maior exportador de cacau, hoje figura na sétima posição no mercado mundial, mas com perspectivas de aumentar sua participação, principalmente na venda de produtos com maior valor agregado, como chocolate fino.

Segunda Azevedo (2016), em matéria da Revista Exame, cada brasileiro consome, em média, 2,5kg de chocolate, anualmente. Em se tratando de região, o Sul é onde as pessoas mais consomem (4,5 kg/ano). Referente aos hábitos de consumo em se tratando de classe social e mantidas as devidas proporções, as mais altas consomem mais no inverno e nas versões ao leite e amargo. Já nas mais baixas, o chocolate é lembrado como uma opção de presente, preferencialmente na versão branca.

Entre janeiro e setembro de 2020, a taxa de entrada da categoria de chocolates nos lares brasileiros foi de $90,1 \%$, segundo pesquisa realizada pelo Instituto Kantar, encomendada pela Associação Brasileira da Indústria de Chocolates, Amendoim e Balas (SUNDRÉ, 2021). Em relação ao faturamento da categoria, houve um acréscimo de $9 \%$ em comparação com o mesmo período de 2019, atingindo o valor de $\mathrm{R} \$ 5,4$ bilhões até setembro, estimulado pelo consumo doméstico.

Ainda segundo Sundré (2021), as análises da Kantar indicam que as vendas de chocolate no varejo tradicional aumentaram durante a pandemia, como consequência de um novo comportamento do consumidor, que deu preferência aos pontos de venda localizados próximos às suas casas. Para o presidente da Abicab, o movimento já era esperado, considerando que a venda do produto se manteve, mesmo com parte do comércio fechado. "Apesar do crescimento de outros canais de venda, o varejo tradicional ainda se manteve relevante durante o período mais crítico da pandemia".

Contribuindo com o exposto acima, segundo Coura (2020), durante o período da quarentena, as pessoas passaram a consumir doces com mais frequência, em mais dias da semana. Abaixo, está o Gráfico 1, retratando o aumento do consumo por faixa etária.

Com isso, pode-se verificar que apesar da pandemia ter criado vários empecilhos neste mercado, sendo um produto não considerado essencial, os consumidores enxergaram no chocolate uma forma de tornar seus dias de quarentena mais alegres e menos angustiantes.

Vale lembrar que, anos atrás, o chocolate era visto somente como uma opção de presente ou sobremesa. Hoje, ele é mais do que isso, é visto como um alimento que traz energia, e que também, produz um momento de conforto e bem estar ao seu consumidor.

Com isso, pode-se dizer que investir no mercado de chocolates é um desafio, mas ao mesmo tempo, um excelente negócio, com 


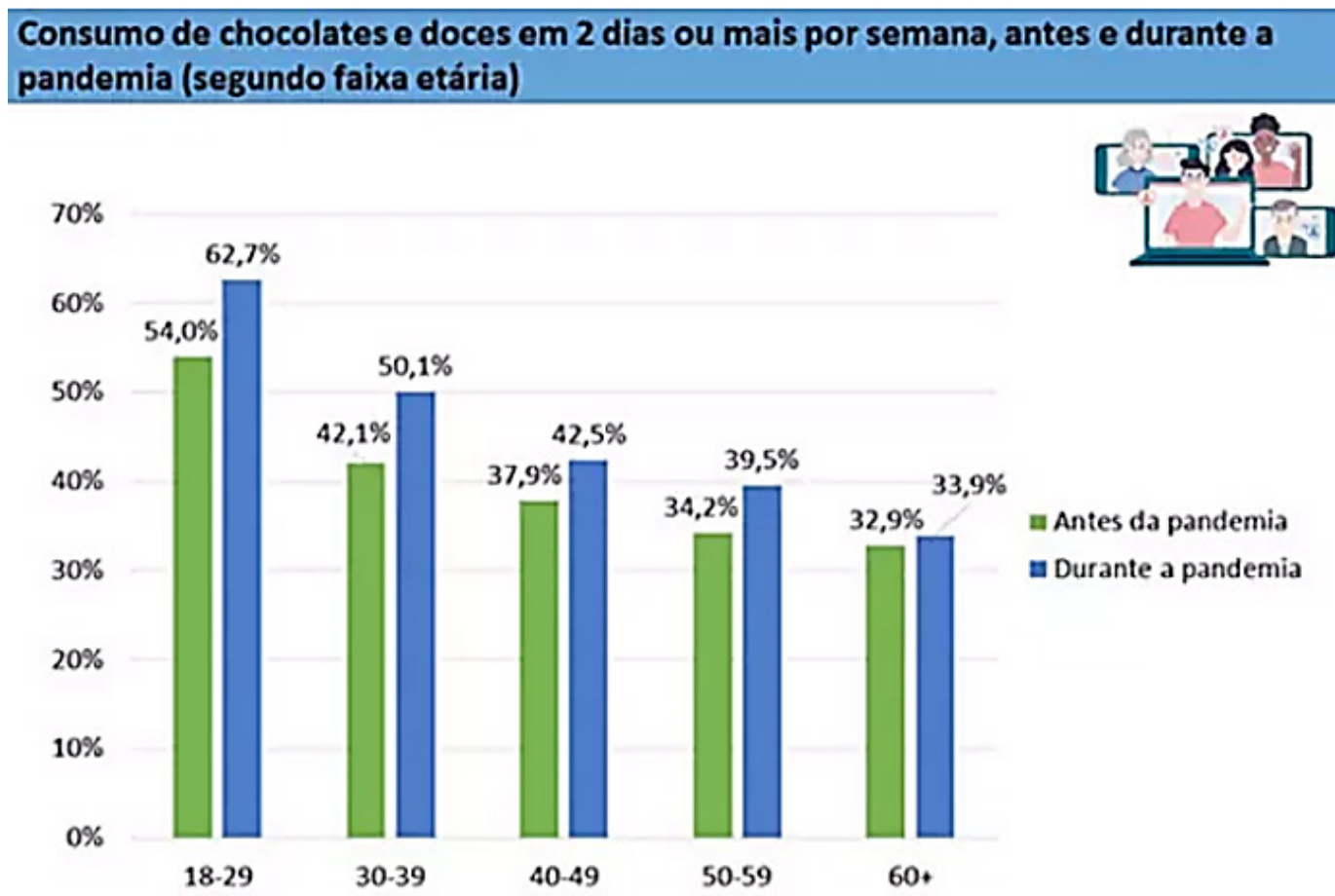

Autor: COURA (2020).

boas perspectivas, visto a lucratividade ser alta. Claro que, as marcas devem apostar cada vez mais na criatividade para fazer com que o consumidor as escolham, dentre todas as outras marcas disponíveis no mercado precisam mostrar seu diferencial, seja ele no preço, na qualidade, na variedade, no sabor, etc.

\section{Procedimentos metodológicos}

Este estudo tem como característica ser uma pesquisa inicialmente exploratória, com levantamento bibliográfico, o qual ajudou a definir o tema e os conceitos relevantes para o estudo. Também é classificada como descritiva, pelo fato de buscar explicar as características do consumidor de chocolates em relação aos atributos que geram valor à marca.
A pesquisa é de natureza quantitativa, pois utiliza-se de técnicas estatísticas para compreender as relações entre o consumidor e o mercado.

Além disso, caracteriza-se como uma pesquisa empírica, onde foi realizada a coleta de dados através do trabalho de campo com os consumidores de chocolates na cidade de Erechim/RS, com o objetivo de fazer a análise e interpretação dos dados, a fim de compreender e explicar o assunto pesquisado.

Nesse sentido, a população deste estudo são os consumidores de chocolates da cidade de Erechim/RS.

Considerando a característica quantitativa do presente estudo, o método proposto para a análise e interpretação dos dados foi a verificação através de gráficos.

A pesquisa foi enviada a 500 pessoas, no período de 22/03/2021 a 24/04/2021. Destas, 
obteve-se o retorno de 143 respondentes, com taxa de retorno de $29 \%$. Considerando a dificuldade em ter o retorno esperado dos respondentes, pode-se considerar uma taxa aceitável para o que o estudo se propõe, possibilitando a geração de números que representam uma tendência nos hábitos de consumo dos consumidores de chocolate, em Erechim/RS. A seleção das 500 pessoas para quem a pesquisa foi enviada ocorreu de forma aleatória, porém voltada para pessoas que residissem em Erechim e que consumissem chocolate, conforme explicito no cabeçalho da pesquisa e também na orientação quando a mesma foi enviada.

A coleta de dados teve início com dados secundários, onde o processo de coleta foi em bancos oficiais, que reúnem periódicos, artigos, dissertações, teses e outros estudos sobre os temas da pesquisa.

Posterior a isso, foram coletados os dados primários, com a pesquisa de campo. A técnica adotada foi uma survey, por meio de um questionário eletrônico. A técnica survey abrange um questionário que se destina a amostra do estudo, com o objetivo de obter informações peculiares dos entrevistados (MALHOTRA, 2006).

O questionário eletrônico foi enviado aos entrevistados por meio da ferramenta de formulários do Google (Google Forms). Nesta ferramenta, as respostas da pesquisa são coletadas de forma organizada e automática, disponibilizando informações e gráficos em tempo real. $\mathrm{O}$ envio do formulário ocorreu por meio de E-mail, WhatsApp e mensagens através do Facebook e Instagram.

\section{Resultados}

A apresentação de resultados foi dividida em dois Módulos, conforme o questionário aplicado, separados em Módulo I - Perfil dos Entrevistados e Módulo II - Hábitos de Consumo.

Para início da análise, considerando o Módulo I, verificou-se o gênero dos entrevistados. De acordo com a Tabela I, observa-se que o gênero predominante dos respondentes é feminino, sendo que estes representam 99 mulheres (69\%) seguido de 44 homens (31\%). Em relação a faixa etária, identifica-se a predominância de 25 a 35 anos, correspondendo a 78 respondentes (54\%), seguido da faixa etária de acima de 35 anos, com 47 respondentes $(33 \%)$, e de 17 a 24 anos correspondendo a 17 respondentes (12\%). A faixa etária menor de 17 anos obteve menor representatividade entre os consumidores, correspondendo a 1 respondente (1\%).

A respeito da renda familiar, observou-se que 55 respondentes possuem renda de 1 a 3 salários-mínimos, correspondendo a $39 \%$ dos entrevistados. Posteriormente, identificou-se a renda entre 4 a 6 salários-mínimos, com 55 respondentes (38\%) e, com menor índice, vê-se a opção da renda entre acima de 6 salários-mínimos, com 33 respondentes (23\%).

Com relação a ocupação dos entrevistados, o maior índice é profissional de empresa privada, que corresponde a opção de 106 respondentes $(74 \%)$. Com índices menores aparecem as ocupações de profissional liberal, com 19 respostas (13\%), estudante com 8 respondentes $(6 \%)$, servidor público com 7 respondentes $(5 \%)$, aposentado com 2 respondentes $(1 \%)$ e por fim, desempregado com 1 respondente (1\%).

Quanto ao Módulo II, abaixo seguem gráficos explicitando as informações encontradas.

Iniciaram-se as questões sobre os hábitos de consumo perguntando com que frequência os entrevistados consumiram chocolate. Conforme pode-se observar no Gráfico 2, $47 \%$ dos entrevistados adquirem chocolates semanalmente, $29 \%$ mensalmente, $19 \%$ quinzenalmente e $5 \%$ com frequência diária. 


\section{Gênero}

\begin{tabular}{|c|c|c|}
\hline & Frequência & Percentual \\
\hline Feminino & 99 & $69,00 \%$ \\
\hline Masculino & 44 & $31,00 \%$ \\
\hline \multicolumn{3}{|c|}{ Faixa etária } \\
\hline & Frequência & Percentual \\
\hline Menor de 17 anos & 1 & $1,00 \%$ \\
\hline De 17 a 24 anos & 17 & $12,00 \%$ \\
\hline De 25 a 35 anos & 78 & $54,00 \%$ \\
\hline Acima de 35 anos & 47 & $33,00 \%$ \\
\hline \multicolumn{3}{|c|}{ Renda Familiar } \\
\hline & Frequência & Percentual \\
\hline De 1 a 3 salários mínimos & 55 & $39,00 \%$ \\
\hline De 4 a 6 salários mínimos & 55 & $38,00 \%$ \\
\hline Acima de 6 salários mínimos & 33 & $23,00 \%$ \\
\hline \multicolumn{3}{|c|}{ Ocupação } \\
\hline & Frequência & Percentual \\
\hline Aposentado & 2 & $1,00 \%$ \\
\hline Estudante & 8 & $6,00 \%$ \\
\hline Profissional de empresa privada & 106 & $74,00 \%$ \\
\hline Profissional liberal & 19 & $13,00 \%$ \\
\hline Servidor Público & 7 & $5,00 \%$ \\
\hline Desempregada & 1 & $1,00 \%$ \\
\hline
\end{tabular}

Gráfico 2 - Frequência de consumo

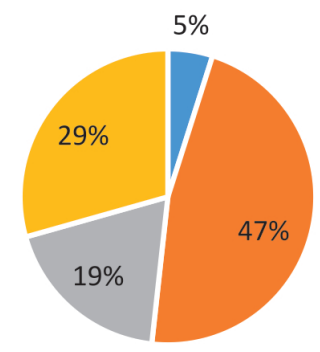

- Diária - Semanal - Quinzenal - Mensal
Quando questionados sobre qual fator mais considerável no momento da compra de um chocolate (Gráfico 3), 45\% dos respondentes citam a qualidade dos produtos, seguido do sabor com $35 \%$, preço com $10 \%$, marca com $5 \%$, aparência com $4 \%$ e apenas $1 \%$ dos respondentes acredita que o aroma é o fator mais relevante.

Referente à pergunta sobre o que os entrevistados acreditam ser um diferencial em marcas de chocolate, conforme Gráfico 4, pode-se observar que mais da metade dos entrevistados acredita que um diferencial na marca é ter produtos reconhecidos pela qualidade, citada por $54 \%$ dos entrevista- 
dos, seguido de $17 \%$ dos respondentes que acreditam que um diferencial é preço adequado, e com mesmo percentual, ter opções diferenciadas de sabor. Também, $8 \%$ dos respondentes citaram embalagem atraente e $4 \%$ citaram ser as ações de marketing que a marca promove, como sempre os principais diferencias. A opção tamanho, não foi considerada por nenhum dos respondentes, portanto, segundo os participantes da pesquisa, não é um diferencial para os produtos da marca.

Gráfico 3 - Fator mais considertado no momento da compra

$=$ Aparência $=$ Aroma $=$ Marca
$=$ Preço $=$ Qualidade $=$ Sabor

Gráfico 4 - Diferenciais em marcas de chocolate

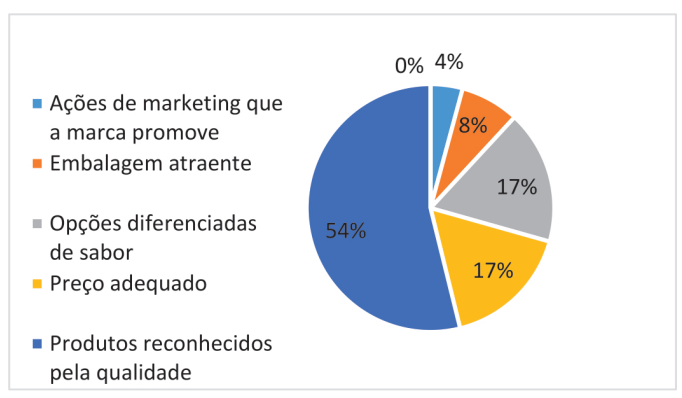

Quando questionados sobre de que forma os entrevistados fazem suas compras, se por meio físico ou virtual (Gráfico 5), 95\% dos entrevistados afirmaram fazê-las em lojas físicas, enquanto $5 \%$ fazem em ambas as formas, ou seja, por meio físico e virtual. Sobre adquirir chocolate somente através de lojas virtuais, nenhum entrevistado optou por este formato.
Gráfico 5 - Por qual meio a compra de chocolates é feita

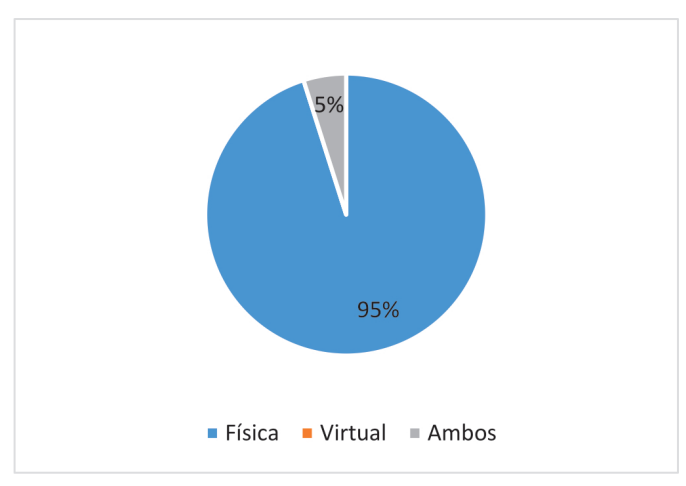

A nona questão do questionário é super importante para a pesquisa, pois questiona se esses consumidores são fiéis a suas marcas preferidas de chocolate (Gráfico 6). Como resposta, 50\% dos respondentes afirmaram que não são fiéis, $28 \%$ se dizem fiéis à marca e $22 \%$ optaram pela opção "talvez".

\section{Gráfico 6 - Fidelidade à marca}

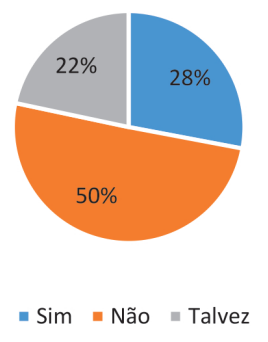

Buscando confirmar os dados da questão anterior, questionou-se se os entrevistados estivessem no local de compra e não encontrassem o produto desejado, se iriam até outro local para adquiri-lo ou comprariam qualquer outro produto, de outra marca (Gráfico 7).

Como resposta, $72 \%$ dos respondentes afirmaram que comprariam qualquer outro produto (ou seja, não seriam fiéis) e $28 \%$ buscariam a marca em outro ponto de venda. 
Gráfico 7 - Fidelidade à Marca II

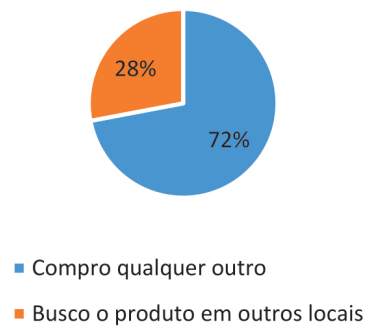

Quanto à marca preferida de chocolate dos respondentes, no (Gráfico 8), estão todas as que foram citadas. Dentre elas, tem-se: Trento (29\%), Lacta e Nestlé (19\%), Ferrero (12\%), Cacau Show (10\%), Garoto (5\%), Mars (3\%), Milka (2\%) e Divine (1\%). Uma das respostas foi inválida (1\%).

Gráfico 8 - Marcas preferidas dos consumidores

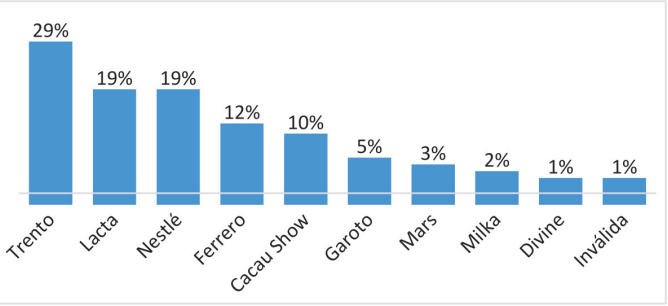

No que tange ao motivo de preferência pela marca citada acima pelos respondentes (Gráfico 9), 83\% afirma ser a qualidade o motivo principal pela escolha do produto da marca, seguido de $10 \%$ que apontaram ser a variedade dos produtos, $4 \%$ o preço e $3 \%$ a tradição da marca. A opção embalagem não foi citada por nenhum dos respondentes $(0 \%)$.

Questionados sobre como conheceram a marca (Gráfico 10), 38\% afirmaram que tomaram conhecimento através da indicação de amigos, 27\% através de propagandas na $\mathrm{TV}, 21 \%$ por propagandas em redes sociais, e com menor percentual, temos $6 \%$ que conheceram a marca através do ponto de venda, $3 \%$ no trabalho. Com este mesmo percentual aparece o conhecimento da marca através da degustação e representando $1 \%$, respondentes que ganharam chocolate da marca de presente.

\section{Gráfico 9 - Motivo da preferência da marca}

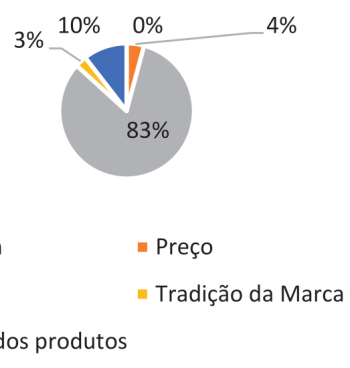

Gráfico 10 - Como conheceu a marca?

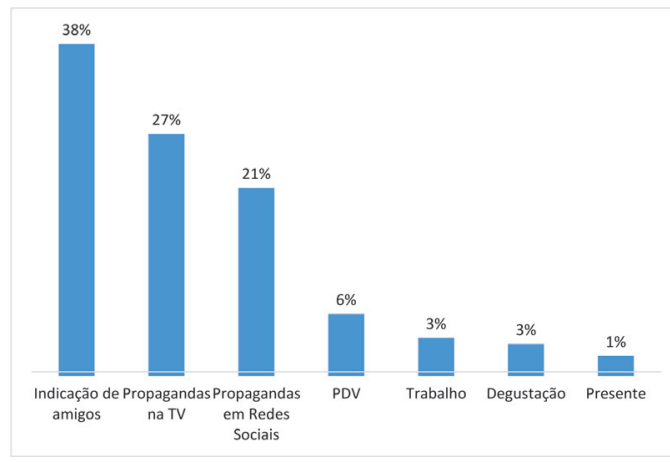

Gráfico 11 - Facilidade de encontrar o produto na cidade

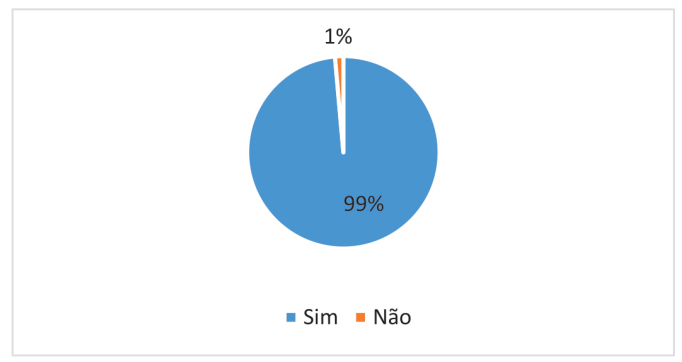

Quanto a questão que pergunta se na cidade de Erechim/RS (Gráfico 11), os respondentes têm facilidade em encontrar os produtos da marca, 99\% afirmaram que sim, enquanto que somente $1 \%$ apontou que tem dificuldade em localizar os produtos. 
No que se refere à finalidade da compra de chocolate (Gráfico 12), 62\% apontaram ser para consumo próprio, $35 \%$ para ambos os casos, ou seja, consumo próprio e presente, e apenas 3\% apontaram adquirir somente para presente.

\section{Gráfico 12 - Finalidade da compra}

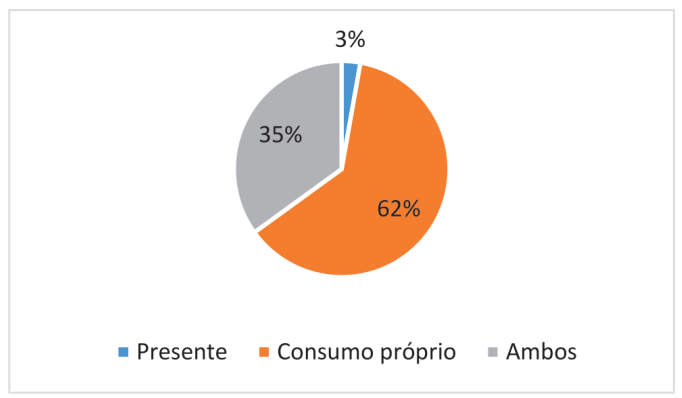

Foi questionado se, no caso da compra para presente, em qual data comemorativa a compra que mais ocorria (Gráfico 13). Mais da metade dos respondentes, $56 \%$, citaram a Páscoa como data comemorativa em que mais compra chocolate. Depois, com percentuais menores, aparecem o Natal com 23\%, aniversário com $9 \%$, dia dos namorados com $6 \%$, dia das crianças com $3 \%$ e $1 \%$ para dia das mães. A opção de dia dos pais, não foi citada $(0 \%)$. E, uma das respostas foi invalidada (1\%).

Gráfico 13 - No caso da compra para presente, ocorre em qual data comemorativa:

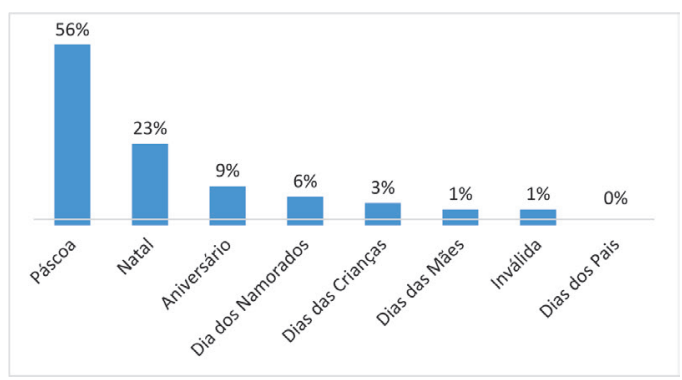

Após todas as questões sobre os hábitos de consumo dos respondentes, a última pergunta foi "se consumir chocolate os deixavam felizes" (Gráfico 14). Nesta, 62\% dos respondentes afirmaram que consumir o produto sempre os deixam felizes; $31 \%$ apontaram que muitas vezes e 7\% optaram por raramente. A opção nunca, não foi selecionada por nenhum dos respondentes $(0 \%)$.

Gráfico 14 - Consumir chocolate te deixa feliz?

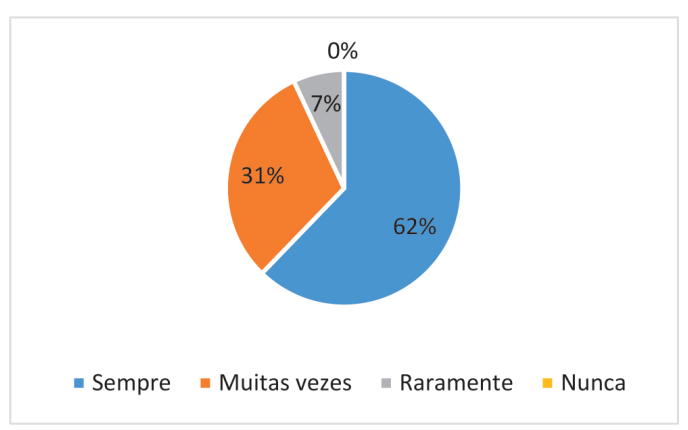

De acordo com os gráficos apresentados, pode-se observar que o chocolate está muito presente na casa das pessoas, pois seu consumo é rotineiro, reiterando os dados de Sundré (2021), onde afirma que o consumo de chocolates aumentou durante a pandemia, consequência de um novo comportamento do consumidor.

$\mathrm{O}$ fator mais citado como motivo da escolha da marca de chocolate pelos consumidores foi a qualidade, assim como o que os consumidores apontaram como sendo um diferencial. AAKER (1998), cita qualidade percebida como um dos elementos da marca, sendo "a percepção que os consumidores têm da qualidade dos produtos e serviços que a empresa trabalha. Os consumidores buscam o menor preço com a maior qualidade dos produtos ou serviços, dessa forma, a qualidade é fator importante e determinante para a empresa, em relação aos seus produtos e serviços, pois está estreitamente ligado ao que o consumidor avalia como importante para si próprio, e que valoriza", confirmando a importância de vender um produto que 
entregue aquilo que o cliente deseja, corroborando com o que o autor Serralvo et al. (2011) coloca, que "as marcas representam uma promessa da garantia da satisfação para o cliente, seu bem-estar e ainda, da expectativa que o bom desempenho do produto irá efetivamente ocorrer após sua compra."

Quanto à fidelidade da marca, a pesquisa aponta que a maioria dos consumidores não é fiel. Analisando essa informação, Keller e Machado (2006), apontam como elementos considerados importante na marca: nome, domínios na internet, logotipos, símbolos, personagem, slogan, jingles e embalagem. Todos eles, contribuem para que a marca fique gravada na mente do consumidor, fazendo com que se lembre dela no ato da compra, adquirindo e se tornando fiel e defensor da marca. Assim como reitera o autor Oliveira et al. (2012), afirmando que um dos elementos considerados mais críticos para formação do valor da marca é estar "na mente dos consumidores".

E também, um ponto interessante citado pelos respondentes, foi que o consumo de chocolate os deixa felizes. Para Keller e Machado (2006, p. 7), “o significado incorporado em uma marca pode ser bastante profundo, e o relacionamento entre ela e o consumidor pode ser visto como um tipo de vínculo ou pacto", ou seja, o cliente ficando satisfeito e feliz com a experiência de consumir aquele produto, certamente fará com que ele reviva isso no momento em que decidir comprar a marca novamente, esperando sentir a mesma sensação.

\section{Conclusão}

Com o objetivo de identificar o perfil do consumidor de chocolates na cidade de Erechim/RS e seus hábitos de consumo, através da análise dos resultados da pesquisa, pode-se reiterar como principais resultados alguns pontos focais para as empresas do ramo.
Dados da pesquisa revelam que $47 \%$ dos respondentes compram chocolate semanalmente, sendo um número expressivo e ótimo para as empresas desta indústria. O chocolate ganhou espaço no mercado no decorrer dos anos, tendo gondolas especiais para eles nos mercados e também, tendo mais aceitação na casa das famílias. Deixando de ser uma compra somente em datas comemorativas, os números mostram que o consumo de chocolate pelas pessoas está se tornando cada vez mais habitual, muito pelo fato de que também, de acordo com a pesquisa, $62 \%$ afirmam que consumir o produto sempre os deixa felizes. Com o dia-a-dia corrido da maioria das pessoas, degustar um chocolate torna-se um momento prazeroso e de bem-estar, sendo um escape ao estresse. Visto também, que $62 \%$ dos entrevistados afirmam que adquirem o chocolate para consumo próprio, reiterando que ele deixou de ser consumido apenas em datas especiais. Contudo, 35\% deles apontam que adquirem chocolate em ambos os casos, para consumo e presente.

Sendo o chocolate um produto de geralmente compra por impulso, é importante que as empresas tenham uma boa distribuição de sua marca, para que esteja presente no maior número de pontos de venda possíveis. Considerando isso e correlacionando com os dados da pesquisa, observa-se que $95 \%$ dos respondentes fazem a compra de seu chocolate de forma física (justamente por ser uma compra de impulso). Sendo assim, cabe também levantar um alerta às empresas que buscam pelo e-commerce para venda de chocolates. É importantíssimo que levantada essa questão, seja feita uma pesquisa de mercado detalhada, com intuito de medir se seu público-alvo realmente consome nessa plataforma, pois no caso da pesquisa em questão, apenas 5\% consideram a forma virtual como meio de compra desse tipo de produto. Na cidade de Erechim/RS, 99\% dos entrevistados afirmaram encontrar o choco- 
late de sua marca preferida, facilmente nos pontos de venda.

Tratando-se de fidelidade à marca, ponto fundamental para o relacionamento entre marca $x$ cliente, pode-se observar que a grande maioria de entrevistados não são fiéis às suas marcas de chocolate. Segundo os dados extraídos da pesquisa, $50 \%$ dos respondentes afirmaram não serem fiéis, e aumentando este número, quando questionados se por acaso, não encontrassem o produto de sua marca no local em que estão, o buscariam em outro local ou comprariam outra marca; $72 \%$ optaram por comprar outra marca no local onde se encontra. Sendo assim, as marcas precisam cada vez mais buscar formas de se relacionar com seus clientes, criar vínculos emocionais, para que eles sejam defensores da marca e realmente tornem-se clientes fiéis, assim, influenciando sua rede de contatos para adquirir sua marca preferida, pois, também, de acordo com a pesquisa, nota-se que $38 \%$ conheceram a marca através da indicação de amigos. Importante, ainda, a aproximação da marca pelas mídias, fazendo campanhas com que o consumidor se identifique. Nos resultados da pesquisa, notou-se também que $27 \%$ conheceram a marca através de propagandas na TV e $21 \%$ por propagandas em mídias sociais. Daí a importância de ter um setor de marketing alinhado com as perspectivas e objetivos da empresa, sabendo qual consumidor deve atingir. De acordo com a pesquisa, $56 \%$ dos respondentes afirmaram que a data comemorativa em que mais compram é a Páscoa, reiterando a importância de ações nas mídias nessa época.

De acordo com a pesquisa, pode-se dizer que a palavra chave para escolha de um chocolate é sua qualidade. Dentre os consumidores entrevistados, $45 \%$ deles consideram a qualidade no ato da compra, assim como $54 \%$ acreditam que esse é um diferencial para a marca. Reiterando essas questões, mostra-se também que $83 \%$ dos respondentes afirmam ser a qualidade o motivo de preferência pela marca. Dessa forma, fica claro que as empresas do ramo precisam ter um bom projeto de pesquisa e desenvolvimento, estruturado, para lançar o produto com sua máxima qualidade percebida, pois é um fator que o consumidor valoriza muito, sendo determinante para sua escolha ou não pela marca.

Dentre as 9 marcas de chocolate citadas na pesquisa, a marca mais lembrada foi Trento (29\%), seguida de Lacta e Nestlé (19\%), Ferrero (12\%) e Cacau Show (10\%), que foram os maiores percentuais. Vale ressaltar que a marca Trento é fabricada na cidade de Erechim/RS, onde a pesquisa foi aplicada, podendo assim ser mais lembrada regionalmente.

Com o mercado cada vez mais competitivo, estudos como este auxiliam as marcas a melhor se posicionaram no mercado perante seus consumidores, pois demonstram os atributos que geram a valorização da marca. Keller e Machado (2006) reiteram a importância de as marcas entregarem valor consistente ao consumidor, mostrando todo o conjunto de benefícios que pretendem entregar.

Mantendo as devidas proporções, de acordo com os dados gerados pela pesquisa, pode-se confirmar os aspectos primordiais que as marcas devem se atentar no momento de elaborar suas estratégias, com intuito de que sejam assertivas na comunicação com seu público alvo, tendo um plano de distribuição de seus produtos, se atentando à qualidade oferecida para o mercado, buscando, acima de tudo, estabelecer uma relação de confiança com seu consumidor, mostrando o que de fato a empresa está entregando ao mercado, qual seu diferencial e qual é o valor do produto oferecido.

Como recomendação para estudos futuros, sugere-se replicá-lo com finalidades semelhantes, de acordo com a região de atuação da marca, tornando-se possível a comparação dos resultados obtidos neste estudo, como 
também comparar outras variáveis. Também, para os gerentes de empresas no setor, sugere-se trabalhar o brand equity em suas organizações e em seus concorrentes, dando maior importância para a gestão e construção de marcas, a fim de se obter um melhor posicionamento e elaboração de estratégias mercadológicas mais assertivas, para que possam também comunicar seu produto ou serviço de forma mais eficaz e entregar valor aos seus consumidores. Além disso, sugere-se também para estudos futuros, pesquisar sobre $o$ atributo qualidade, a fim de identificar qual é a percepção dos consumidores referente a esse aspecto, assim como avaliar a importância da distribuição (logística) como fator fundamental para o sucesso da compra pelo consumidor, pois o produto precisa estar disponível, considerando que a falta do mesmo faz com que ele opte por outra marca.

\section{REFERÊNCIAS}

AAKER, D. Relevância de marca: Como deixar seus concorrentes para trás. Porto Alegre: Bookman, 2011.

AAKER, D. A. Marcas: Brand Equity gerenciando o valor da marca.13. ed. São Paulo: Elsevier, 1998.

AZEVEDO, R A relação do brasileiro com o chocolate. 2016. Disponível em: https:/exame.com/ brasil/a-relacao-do-brasileiro-com-o-chocolate/. Acesso em: 30 mar. 2021.

CHURCHILL JUNIOR, G. A.; PETER, J. P. Marketing: Criando valor para os clientes. 2. ed. São Paulo: Saraiva, 2010.

CHURCHILl JUNIOR, G. A.; PETER, J. Marketing: Criando valor para os clientes. 3. ed. São Paulo: Saraiva, 2012.

COURA, P. Nada de salada ou frutas: consumo de doce e bebida alcoólica subiu na quarentena. 2020. Disponível em: https://www.otempo.com.br/interessa/nada-de-salada-ou-frutas-consumo-dedoce-e-bebida-alcoolica-subiu-na-quarentena-1.2341665. Acesso em: 30 mar. 2021.

DIAS, S. R. et al. Gestão de Marketing. 2. ed. São Paulo: Saraiva, 2010.

FROEMMING, L. M. S. et al. O comportamento do consumidor e do comprador. Ijuí: Unijui, 2009. $104 \mathrm{p}$.

INPI, Instituto Nacional da propriedade industrial. Marcas. 2017. Disponível em: http://www. marcasepatentes.pt/index.php?section=125. Acesso em: 30 mar. 2021.

KOTLER, P.; KELLER, K. L. Administração de Marketing: A bíblia do marketing. 12. ed. São Paulo 2006: Pearson Prentice Hall, 2006.

KOTLER, P. KARTAJAYA, H.; SETIAWAN, I. Marketing 3.0: As forças que estão definindo o novo marketing centrado no ser humano. Rio de janeiro: Elsevier, 2010.

KELLER, K. L.; MACHADO, M. Gestão Estratégica de Marcas. São Paulo: Pearson Prentice Hall, 2006.

MARTINS, J. R. Branding: Um manual para você criar, gerenciar e avaliar marcas. 3. ed. [s.i.]: Global Brands, 2006.

MALHOTRA, N. K. Pesquisa de Marketing: Uma Orientação Aplicada. 4. ed. Porto Alegre: Bookman, 2006. 
MANCINI, C. O doce mercado de chocolate no Brasil. 2019. Disponível em: http://www. negociosemmovimento.com.br/economia/o-doce-mercado-de-chocolate-no-brasil/. Acesso em: 26 mar. 2021.

MINISTÉRIO DA AGRICULTURA, PECUÁRIA E ABATECIMENTO. Brasil quer ganhar posições na produção mundial de cacau e chocolate. 2020. Disponível em: https:/www.gov.br/ agricultura/pt-br/assuntos/noticias/brasil-quer-retomar-protagonismo-no-cenario-global-de-cacau-echocolate. Acesso em: 03 maio 2021.

OLIVEIRA, B. et al. (Org.). Gestão de Marketing. São Paulo: Pearson Prentice Hall, 2012.

PETER, J. P.; OLSON, J. C. Comportamento do consumidor e Estratégia de Marketing. 8. ed. São Paulo: Mcgraw-hill, 2009.

SERRALVO, F. A. et al. (Org.). Gestão de marcas no contexto brasileiro. São Paulo: Saraiva, 2011.

SCHIFFMAN, L. G.; KANUK, L. L. Comportamento do consumidor. 9. ed. Rio de Janeiro: Ltc, 2015.

SOLOMON, M. Os segredos da mente dos consumidores. N. Famalicão, Portugal: Centro Atlântico, 2009.

SUDRÉ, L. Mais de $\mathbf{9 0 \%}$ dos brasileiros compraram chocolate para consumo em casa em

2020. 2021. Disponível em: https://tribunademinas.com.br/noticias/defesa-consumidor/10-01-2021/ mais-de-90-dos-brasileiros-compraram-chocolate-para-consumo-em-casa-em-2020.

html\#: :text=Entre $\% 20$ janeiro $\% 20 \mathrm{e} \% 20$ setembro\%20de,Amendoim $\% 20 \mathrm{e} \% 20 \mathrm{Balas} \% 20$ (Abicab). Acesso em: 29 mar. 2021. 
